\title{
ARQUEOMETRIA E O SÍTIO ARQUEOLÓGICO PEDRA DO CANTAGALO I: UMA ESTRATÉGIA DE INVESTIGAÇÃO COMO MODELO PARA A AMÉRICA DO SUL
}

ARCHAEOMETRY AND THE ARCHAEOLOGICAL SITE PEDRA DO CANTAGALO

I: A RESEARCH STRATEGY AS MODEL FOR SOUTH AMERICA

Luis Carlos Duarte Cavalcante

Como citar este artigo:

CAVALCANTE, Luis Carlos Duarte.Arqueometria e o sítio arqueológico Pedra do Cantagalo I: uma estratégia de investigação como modelo para a América do Sul. In: Cadernos do Lepaarq, v. XV, n.30., p. 315-326, Jul-Dez. 2018. 


\title{
Arqueometria e o sítio arqueológico Pedra do Cantagalo I: uma estratégia de investigação como modelo para a América do Sul
}

\author{
Luis Carlos Duarte Cavalcante*
}

Resumo: A Pedra do Cantagalo I é um sítio arqueológico localizado na área rural do município de Piripiri, estado do Piauí, Brasil. Consiste em um abrigo sob-rocha arenítica, cujas saliências e reentrâncias estão decoradas com mais de 1.950 pinturas rupestres representando figuras abstratas, propulsores de dardos, carimbos de mãos humanas, antropomorfos e zoomorfos, realizados em padrões policromáticos. Além da elevada densidade de inscrições pré-históricas e da policromia, esse sítio também se destaca pela recorrência dos motivos pintados e pela sobreposição deles entre si. Nos sedimentos superficiais foram encontrados fragmentos cerâmicos, líticos e ocres. Carvões residuais encontrados em fogueiras bem estruturadas, evidenciadas em recentes escavações neste abrigo, foram datados pelo método do ${ }^{14} \mathrm{C}$ como sendo de $1.180 \pm 30$ anos antes do presente; em estratigrafia também foram evidenciados materiais cerâmicos, líticos e ocres vermelhos e amarelos. Neste artigo são reportadas as estratégias analíticas de campo e de laboratório utilizadas na investigação desse importante sítio arqueológico e dos testemunhos de atividade humana pré-histórica nele existentes ou dele coletados. Os exames físicos, a caracterização químicomineralógica dos materiais, o monitoramento das condições ambientais e as prospecções no entorno foram primordiais.

\section{Palavras-Chave:}

Pinturas rupestres; Ocres; Cerâmica arqueológica; Arqueologia; Arqueometria.

\begin{abstract}
Pedra do Cantagalo I is an archaeological site located in the rural area of the municipality of Piripiri, Piauí state, Brazil. It consists of a sandstone shelter decorated with more than 1,950 rupestrian paintings representing abstract figures, spear-throwers, human handprints, and anthropomorphic and zoomorphic figures in polychromatic patterns. In addition to the high density of prehistoric inscriptions and polychrome paintings, this site also stands out due to the recurrence of painted motifs and to the overlapping of the paintings. Ceramic materials, lithics and ochres were found in the sediments. Residual charcoals found in remnants of well-structured hearths, as recently evidenced from excavations in this shelter were AMS (accelerator mass spectrometry) ${ }^{14} \mathrm{C}$-dated as being from $1,180 \pm 30$ years before present; in stratigraphy, ceramic materials, lithics and red and yellow ochres were also evidenced. In this paper the field and laboratory analytical strategies used in the investigation of this important archaeological site are report as well as the evidence of prehistoric human activity contained within or collected from the site. The investigative techniques included physical examinations of the site, chemical-mineralogical characterization of the materials, monitoring of the environmental conditions and prospections in nearby areas.
\end{abstract}

\section{Keywords:}

Rupestrian paintings; Ochres; Archaeological ceramics; Archaeology; Archaeometry.

\footnotetext{
* Doutor em Ciências - Química, pela Universidade Federal de Minas Gerais (UFMG), Brasil. Professor da Universidade Federal do Piauí, Teresina (UFPI), Brasil. Bolsista de Produtividade em Pesquisa, pelo Conselho Nacional de Desenvolvimento Científico e Tecnoló-gico (CNPq), Brasil. E-mail: cavalcanteufpi@yahoo.com.br
} 


\section{O SÍTIO ARQUEOLÓGICO PEDRA DO CANTAGALO I: UMA BREVE DESCRIÇÃO GERAL}

A Pedra do Cantagalo I é um grande abrigo rochoso esculpido por erosão diferencial em arenito típico da Formação Cabeças (de idade Devoniana, com a base no estágio Givetiano e o topo atingindo a porção inferior do estágio Fameniano), Membro Oeiras, localizado na área rural do município de Piripiri, no Norte do estado do Piaú, em um pequeno povoado conhecido como Jardim (CAVALCANTE; RODRIGUES, 2010). É exatamente nas paredes, reentrâncias e saliências rochosas desse abrigo que se encontram mais de 1.950 pinturas rupestres, representando figuras abstratas (a maioria com tendência geométrica), carimbos de mãos humanas, zoomorfos, propulsores de dardos e alguns poucos antropomorfos, nas cores preta, amarela, cinza, branca, rosa, vinho, alaranjada e, majoritariamente, em diferentes tonalidades da cor vermelha (CAVALCANTE; RODRIGUES, 2010; Figura 1). Os painéis pictóricos apresentam (i) expressiva densidade de pinturas rupestres, distribuídas desde a base aflorante do abrigo rochoso até aproximadamente 7,2 metros de altura do solo atual, (ii) frequente recorrência das figuras representadas e (iii) sobreposição dos grafismos entre si (CAVALCANTE; RODRIGUES, 2010).

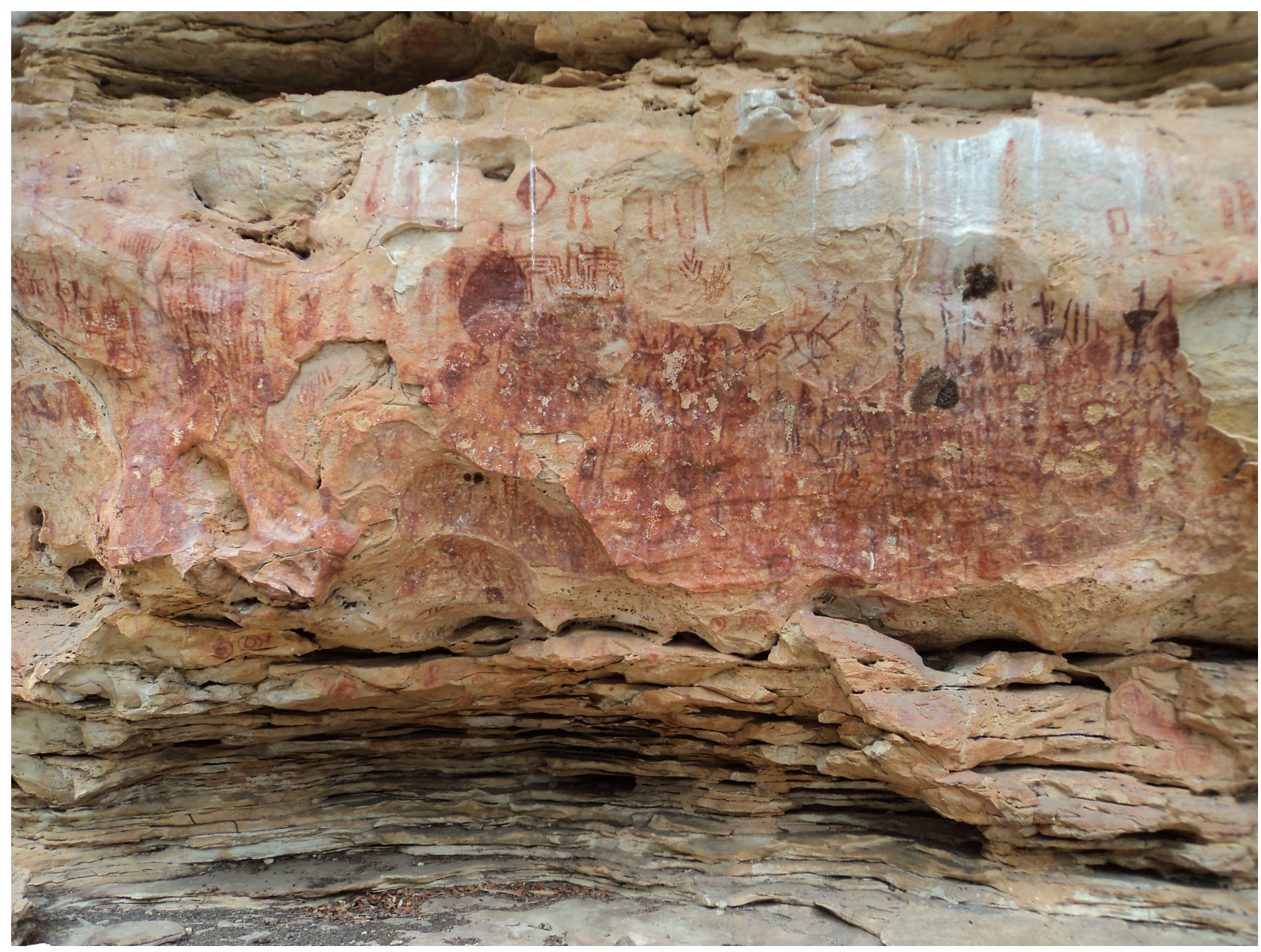

Figura 1: Detalhes das pinturas rupestres do sítio arqueológico Pedra do Cantagalo I.

Harmonicamente, gravuras rupestres também dividem espaço com as pinturas pré-históricas supramencionadas, tanto no piso rochoso quanto nas paredes areníticas, contudo em número expressivamente menor, destacando-se o fato de algumas estarem pintadas (CAVALCANTE; RODRIGUES, 2010). No piso e em algumas plataformas rochosas da área abrigada pontilham dezenas de pilões, presumidamente utilizados para a maceração de ervas e alimentos ou para a eventual preparação de materiais pictóricos (CAVALCANTE et al., 2014). 
Nos sedimentos superficiais, em especial da área protegida sob o teto do abrigo arenítico, foram encontrados diversos vestígios de cultura material, nomeadamente fragmentos cerâmicos exibindo diferentes padrões de queima (Figura 2), líticos lascados e polidos, pigmentos minerais vermelhos (Figura 2) e um moedor impregnado com resíduos de pigmentos amarelos e vermelhos (CAVALCANTE; RODRIGUES, 2010; CAVALCANTE et al., 2014).
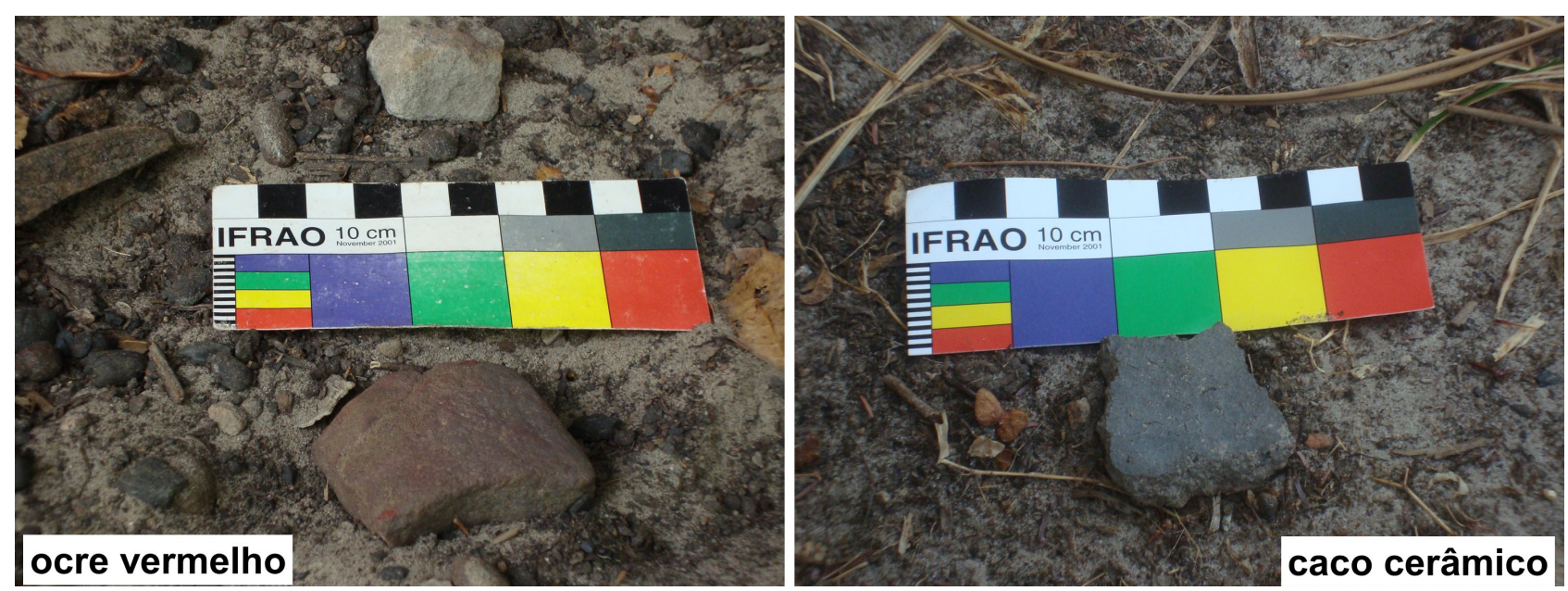

Figura 2: Ocre vermelho e caco cerâmico in situ nos sedimentos superficiais do sítio arqueológico Pedra do Cantagalo I.

Além da coleção excepcional de registros rupestres, a ampla diversidade de vestígios arqueológicos existentes no abrigo Pedra do Cantagalo I conferem a este sítio valor e importância únicos nas pesquisas de arte rupestre do Centro-Norte do Piauí. Portanto, ele é naturalmente um sítio chave para o conhecimento dos grupos humanos pré -históricos da área arqueológica de Piripiri e, consequentemente, a preservação deste patrimônio pré-histórico é de importância primordial e representa um grande desafio. (CAVALCANTE et al., 2014, p. 49).

A exposição a intempéries naturais ao longo do tempo, no entanto, gerou diversos e graves problemas de conservação, muitos deles intensificados pelas intervenções humanas nas últimas décadas. O arenito que serve de suporte às inscrições pré-históricas encontra-se em avançado estado de degradação.

\section{UMA ESTRATÉGIA DE INVESTIGAÇÃO}

Historicamente, o sítio Pedra do Cantagalo I foi registrado pelos pesquisadores do Núcleo de Antropologia Pré-Histórica (NAP) da Universidade Federal do Piauí (UFPI) em outubro de 1997 (IPHAN-UFPI-FUNDEC, 1997), contudo, começou a ser investigado contínua e sistematicamente apenas a partir de outubro de 2009 (CAVALCANTE et al., 2014). Desde então, uma estratégia investigativa com diversas frentes de atuação tem sido implementada, em um esforço para obter um acervo de dados experimentais a partir do qual evidências suficientemente consistentes e seguras possam possibilitar o acesso à pré-história desse sítio arqueológico. Os diversos tipos de abordagens empreendidas são descritos a seguir.

\section{Levantamento geral do sítio arqueológico}

O levantamento geral do sítio arqueológico constou de: obtenção das coordenadas geográficas; altimetria em relação ao nível médio do mar; direção geográfica da abertura da área decorada com as inscrições rupestres; catalogação de diversos aspectos, como tipo de suporte rochoso; divisão das concentrações das inscrições rupestres em painéis pictóricos; determinação geral das alturas mínima e máxima dos registros gráficos em relação ao solo atual; dimensionamento dos painéis pictóricos e da área decorada como um todo; e preenchimento de fichas técnicas e atualização dos dados cadastrais (CAVALCANTE; RODRIGUES, 2010). 
Como parte desta etapa dos trabalhos, também foi realizada a identificação da vegetação que floresce no bloco arenítico no qual o abrigo rochoso encontra-se esculpido, e em seu entorno imediato, do mesmo modo que foi feito o levantamento da fauna que habita ou frequenta o sítio arqueológico (CAVALCANTE; RODRIGUES, 2010). O auxílio dos moradores locais mais próximos ao abrigo rupestre foi objetivamente de grande importância em todas as expedições de campo.

\section{Levantamento das inscrições rupestres pré-históricas}

O levantamento das inscrições rupestres consistiu no detalhamento de aspectos como os tipos de figuras que aparecem representadas, as cores usadas pelos autores pré-históricos para a confecção das inscrições; a quantidade de figuras que é possível discernir atualmente; as dimensões dos grafismos; a largura média dos traços gráficos; a recorrência das figuras; a ocorrência ou não de sobreposições de figuras ou de manchas de tinta entre si; o registro fotográfico panorâmico e de detalhes das inscrições, com e sem escala (CAVALCANTE; RODRIGUES, 2010). Nesta etapa também foi incluído o levantamento das gravuras rupestres e dos pilões existentes nas plataformas e no piso arenítico do abrigo rochoso.

\section{Levantamento dos problemas de conservação}

O levantamento dos principais problemas de conservação que agridem o sítio arqueológico como um todo, e em especial a integridade das inscrições rupestres, considerou diversos aspectos como a ocorrência ou não de fissuras/trincas no arenito suporte; escamações da fina película protetora da superfície da área rochosa com erosão alveolar, sobre a qual comumente as pinturas rupestres são encontradas em sítios arqueológicos; desplacamentos do arenito, quando blocos maiores se desprendem do substrato rochoso; identificação de biodepósitos, como ninhos de insetos construtores (vespas de diferentes espécies, cupins, etc.), dejetos de animais (como mocós, gados bovinos, caprinos e ovinos, etc.); ocorrência ou não de eflorescências salinas, tanto causadas por drenagens de água de chuvas quanto resultantes de migração do interior do arenito suporte; manchas de cores variadas, causadas por microrganismos, briófitas, deposição de fuligem (oriunda de queimadas pontuais no próprio bloco rochoso ou em suas proximidades), ou resultantes de pontos de drenagens de águas de chuva ou com origem em infiltrações; plantas presas ao substrato rochoso (CAVALCANTE; RODRIGUES, 2010). Além dos mais variados problemas de conservação de origem natural, investigaram-se também os resultantes de intervenções humanas, intencionais ou não, recentes, como pichações pintadas, riscadas ou gravadas; lixo deixado pelos visitantes; manchas causadas por deposição de fuligem; dejetos deixados pelos animais dos moradores da vizinhança, como gados caprinos, ovinos e bovinos; supressão de vegetação nativa para a realização de atividades agropastoris; revolvimento do solo nas proximidades, para a abertura de caieiras e produção de carvão vegetal; entre outros (CAVALCANTE; RODRIGUES, 2010).

\section{Coleta de microamostras contendo filmes de tinta de pinturas rupestres e de eflorescências salinas}

A coleta de microamostras de rocha contendo filmes de tinta de pinturas rupestres foi realizada de modo a contemplar representativamente o máximo de cores e tonalidades de tintas com as quais as figuras rupestres foram confeccionadas (CAVALCANTE, 2012). Uma amostra do substrato rochoso também foi coletada, objetivando conhecer a composição químico-mineralógica do suporte das inscrições pré-históricas. Adicionalmente, foram coletadas ainda amostras de eflorescências salinas, muitas das quais estão cobrindo quase integralmente algumas inscrições arqueológicas.

\section{Coleta de vestígios arqueológicos nos sedimentos superficiais da área abrigada}

Face ao perigo de iminente destruição ou extravio dos vestígios arqueológicos aflorantes nos sedimentos superficiais da área abrigada do sítio Pedra do Cantagalo I, decidiu-se pela coleta dos fragmentos cerâmicos, de alguns poucos líticos lascados e polidos, de raros blocos de ocres vermelhos, além de um moedor contendo resíduos de pigmentos amarelos e vermelhos (CAVALCANTE et al., 2014; Figura 3). 


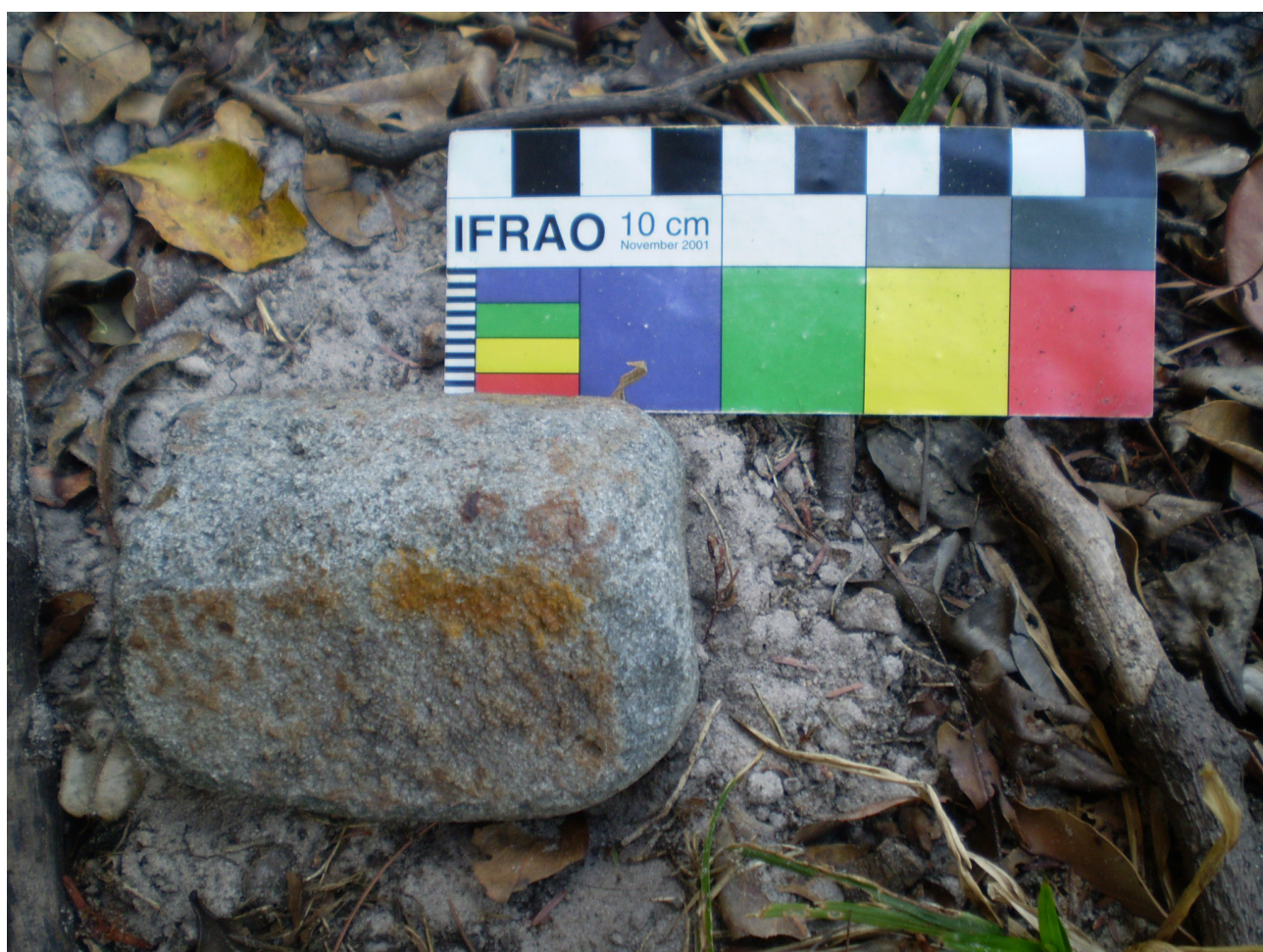

Figura 3: Moedor com resíduos de pigmentos amarelos e vermelhos encontrado in situ nos sedimentos superficiais do sítio arqueológico Pedra do Cantagalo I.

\section{Abertura de sondagens nos sedimentos abrigados}

A realização de uma pequena escavação constou da abertura de duas sondagens (uma de 2 m x 3 m (Figura 4) e outra de $1 \mathrm{~m}$ x $1 \mathrm{~m}$ ) nos sedimentos abrigados do sítio Pedra do Cantagalo I, cujo objetivo primordial foi a evidenciação e coleta de vestígios arqueológicos eventualmente existentes em subsuperfície (CAVALCANTE et al., 2014). O interesse também centrou-se na busca por vestígios em contexto arqueológico mais preservado, além de materiais que possibilitassem a obtenção dos primeiros dados cronológicos para a ocupação humana antiga na área. Sedimentos arqueológicos também foram coletados, visando à prospecção de indicadores químicos de atividade humana pretérita (CAVALCANTE et al., 2014).

\section{Abertura de poços-teste, para a obtenção de sedimentos estéreis}

A abertura de poços-teste para a obtenção de sedimentos estéreis é um aspecto fundamental para a utilização de sedimentos arqueológicos como fontes de indicadores de ocupação humana pré-histórica. Portanto, poços-teste foram abertos no entorno imediato do abrigo Pedra do Cantagalo I, para a comparação de características químico-mineralógicas com os dados correspondentes obtidos para os sedimentos arqueológicos, tanto em termos espaciais quanto ao longo do perfil estratigráfico (CAVALCANTE; SILVA; RODRIGUES, 2016). O objetivo foi conhecer a constituição químico-mineralógica natural dos sedimentos da área (ao modo de um branco analítico), para então ter base de utilização segura dos sedimentos arqueológicos para a identificação de indicadores químicos arqueométricos, conforme mencionado.

\section{Realização de exames físicos das amostras}

Os exames físicos, usando estereomicroscópio de bancada e microscópio óptico digital portátil, constaram de observações detalhadas dos materiais arqueológicos coletados, realizadas com diferentes magnitudes de ampliação, para acesso aos mínimos detalhes morfológicos e topográficos das amostras (CAVALCANTE et al., 2014). O registro foi efetuado com a tomada de imagens digitais e a descrição minuciosa de todos os detalhes morfológicos acessados com cada aumento utilizado. 


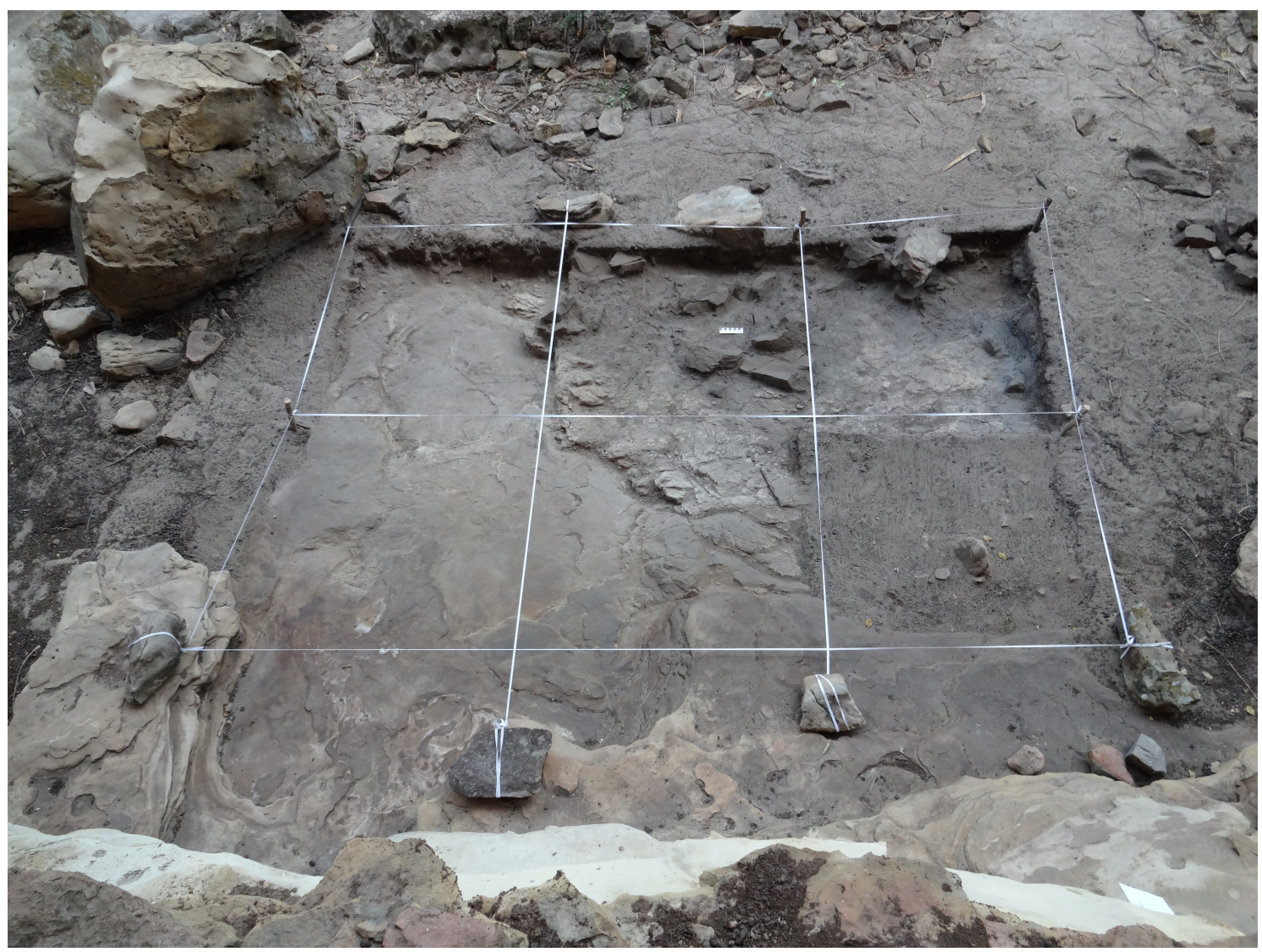

Figura 4: Sondagem 1, aberta no sítio arqueológico Pedra do Cantagalo I.

No caso das microamostras contendo filmes de tinta de pinturas rupestres, o interesse foi (i) a observação da distribuição da tinta pré-histórica sobre a superfície arenítica; (ii) a avaliação da consistência da tinta; (iii) a ocorrência ou não de eflorescências salinas ou de outros depósitos de alteração sobre os filmes pictóricos, entre outros detalhes (SILVA; CAVALCANTE, 2017).

Em relação às cerâmicas arqueológicas, uma atenção especial foi direcionada para o exame (i) dos padrões de queima dos fragmentos investigados (CAVALCANTE; COSTA, 2014); para a identificação (ii) do tipo de pasta cerâmica utilizada na confecção das peças; (iii) dos aditivos eventualmente acrescentados às massas de argila, para a obtenção da plasticidade desejada; e (iv) do tipo de acabamento dado às superfícies interna e externa dos artefatos, entre outros aspectos (OLIVEIRA, 2013).

Uma consequência natural do exame dos fragmentos cerâmicos foi a realização de uma avaliação tipológica preliminar desses vestígios de cultura material, constando adicionalmente ao inventário; documentação fotográfica; confecção de desenhos; elaboração de fichas analíticas (OLIVEIRA, 2013).

\section{Realização de análises químico-mineralógicas dos materiais arqueológicos}

As características químicas, mineralógicas, hiperfinas, magnéticas e morfológicas dos materiais arqueológicos foram acessadas pela utilização de uma conjunção de técnicas analíticas, em especial não-destrutivas e preferencialmente com geometria adequada para análise de superfícies, como no caso dos filmes de tintas de pinturas rupestres.

Conforme mencionado, diversos tipos de materiais arqueológicos foram coletados, de modo que as análises arqueométricas abarcaram igualmente uma ampla gama de diferentes tipos de vestígios, tais como:

- Microamostras de rocha contendo filmes finos de tinta de pinturas rupestres (CAVALCANTE, 2012; CAVALCANTE; ALVES, 2014; CAVALCANTE; SILVA, 2014).

- Eflorescências salinas (CAVALCANTE, 2012). 
- Ocres vermelhos e amarelos coletados dos sedimentos superficiais e das sondagens (CAVALCANTE, 2012; CAVALCANTE et al., 2017; SILVA, 2018).

- Fragmentos de cerâmicas arqueológicas coletados dos sedimentos superficiais e das sondagens (CAVALCANTE; COSTA, 2014);

- Paleossedimentos coletados nas sondagens arqueológicas e, comparativamente, as amostras de sedimentos estéreis dos poços-teste (CAVALCANTE; COSTA, 2015).

Entre as diversas técnicas analíticas utilizadas, constam (i) fluorescência de raios X por dispersão de energia; (ii) análise elementar de carbono por CHN; (iii) microscopia eletrônica de varredura; (iv) espectroscopia de energia dispersiva (inclusive com obtenção de mapas químicos); (v) espectroscopia de absorção na região do infravermelho com transformada de Fourier; (vi) espectroscopia de absorção molecular na região ultravioleta-visível; (vii) espectroscopia Mössbauer do ${ }^{57} \mathrm{Fe}$ em geometria de transmissão de raios gama; (viii) espectroscopia Mössbauer do ${ }^{57} \mathrm{Fe}$ em geometria de retroespalhamento de raios gama; (ix) espectroscopia Mössbauer do ${ }^{57} \mathrm{Fe}$ em geometria de elétrons de conversão; (x) difratometria de raios $\mathrm{X}$ em ângulo de incidência rasante; (xi) difratometria de raios $\mathrm{X}$ convencional pelo método do pó; (xii) espectroscopia Raman; e (xiii) magnetometria de amostra vibrante (CAVALCANTE, 2012; CAVALCANTE et al., 2014).

\section{Obtenção dos primeiros dados cronológicos para o sítio Pedra do Cantagalo I}

A evidenciação de três estruturas de combustão em uma das sondagens que foi aberta no abrigo Pedra do Cantagalo I e a abundância de carvões encontrados possibilitou a obtenção da primeira datação radiocarbônica para a ocupação humana pré-histórica desse sítio arqueológico, $1180 \pm 30$ anos antes do presente (Beta - 420913) (CAVALCANTE et al., 2017). Este é um dado primordial para melhor conhecer a pré-história do centro-norte do Piauí, pois ainda não há datações para outros sítios arqueológicos da área, mesmo se o entorno indireto do sítio Pedra do Cantagalo I for ampliado para um raio de aproximadamente $200 \mathrm{~km}$; as únicas datações existentes para sítios arqueológicos próximos correspondem às problemáticas idades obtidas para alguns sítios cerâmicos junto ao litoral atlântico, no extremo norte piauiense (BORGES, 2010; ARAÚJO, 2014), além, obviamente, das abundantes datações obtidas para os sítios do Parque Nacional Serra da Capivara e do seu entorno (GUIDON; DELIBRIAS, 1986; PEYRE et al., 1998; LESSA; GUIDON, 2002; WATANABE et al., 2003; SANTOS et al., 2003; VALLADAS et al., 2003; KINOSHITA et al., 2008, 2014; PESSIS; GUIDON, 2009; GUIDON; LUZ, 2009; FAURE; GUÉRIN; LUZ, 2011).

As datações obtidas para o Sítio Seu Bode (BORGES, 2010), a partir de três fragmentos cerâmicos coletados em superfície: um com idade estimada entre 2.500 e 2.700 anos, outro entre 726 e 816 anos e o terceiro com uma idade de aproximadamente 410 anos, depõem a favor da problemática cronológica dos sítios arqueológicos do litoral piauiense. É o revolvimento contínuo dos vestígios em ambiente de dunas móveis ou semifixas que dispõe em um mesmo nível cerâmicas com cronologias tão distantes entre si, como 2.700 e 410 anos. O contexto arqueológico de uma área com essas características ambientais está, portanto, seriamente comprometido.

\section{Prospecções de jazidas de pigmentos minerais e de massas de argila no entorno do sítio arqueológico Pedra do Cantagalo I}

Uma vez que ocres e fragmentos cerâmicos foram encontrados tanto nos sedimentos superficiais quanto na subsuperfície do sítio Pedra do Cantagalo I, a realização de prospecções no entorno do bloco arenítico no qual o abrigo encontra-se esculpido constitui-se em um aspecto relevante, visando à identificação de jazidas de pigmentos minerais, que possam ter servido de precursores na preparação dos materiais pictóricos, e de jazidas de massas de argila, que possam ter servido de matéria-prima para a preparação das pastas cerâmicas usadas na confecção dos artefatos correspondentes.

Durante as prospecções realizadas, cinco jazidas de pigmentos minerais (SILVA; CAVALCANTE; FABRIS, 2017) e duas de massas de argila foram identificadas nas proximidades do sítio Pedra do Cantagalo I. Amostras dos pigmentos minerais dessas jazidas foram então coletadas e submetidas às mesmas medidas arqueométricas que foram implementadas para os ocres. 
No caso das jazidas de massas de argila, amostras já foram coletadas para medidas experimentais futuras, usando as mesmas técnicas arqueométricas que foram implementadas para os fragmentos cerâmicos.

\section{Mapeamento da malha hídrica do entorno do sítio Pedra do Cantagalo I}

O mapeamento da malha hídrica do entorno do sítio Pedra do Cantagalo I constou do levantamento dos nascedouros (olhos d'água), córregos, riachos e rios da região. O interesse no mapeamento foi ter uma ideia das distâncias que os grupos humanos que ocuparam ou frequentaram o abrigo Pedra do Cantagalo I tinham que percorrer para ter acesso à água.

Um aspecto considerado importante no levantamento foi a identificação de pelo menos cinco olhos d'água nas proximidades do abrigo arqueológico, os quais alimentam continuamente vários veios d'água da região.

\section{Mapeamento de outros sítios arqueológicos existentes do entorno do abrigo Pedra do Cantagalo I}

O mapeamento de outros sítios arqueológicos eventualmente existentes do entorno do abrigo Pedra do Cantagalo I foi realizado com o intuito de compreender toda a ambiência arqueológica da área, visando prospectar eventuais correlações entre os padrões das inscrições rupestres (tipos de figuras representadas, cores utilizadas na confecção dos grafismos etc.) e os demais tipos de vestígios arqueológicos neles encontrados.

\section{Monitoramento sazonal das condições ambientais do abrigo Pedra do Cantagalo I}

O monitoramento sistemático sazonal das condições ambientais típicas da área em que o abrigo Pedra do Cantagalo I está inserido foi realizado por meio de medidas de temperatura do substrato arenítico (em áreas com e sem inscrições rupestres) e do ar ambiente, bem como pela medição da umidade relativa do ar e da velocidade dos ventos atuantes no sítio (CAVALCANTE; ALVES; SILVA, 2017). Entre os objetivos de tais medidas experimentais, constam obter as amplitudes térmicas do substrato rochoso e do ar, umidade relativa do ar ao longo do dia e em diferentes épocas do ano, para seleção das condições ambientes mais favoráveis à visitação do sítio, e especialmente para tentar compreender como esses parâmetros afetam as condições de conservação do abrigo rochoso e das inscrições pré-históricas.

\section{Monitoramento geral dos problemas de conservação em contínuas expediçães a campo}

O monitoramento geral para avaliar o avanço dos principais agentes, sobretudo naturais, que atuam na degradação do sítio Pedra do Cantagalo I, tem sido realizado em frequentes e contínuas expedições a campo, nas quais observações detalhadas e o registro fotográfico correspondente são efetuados.

Entre outubro de 2009 e agosto de 2017, vinte e quatro expedições foram realizadas ao sítio Pedra do Cantagalo I, ocasiões em que o monitoramento e a documentação fotográfica foram realizados.

Durante esse período foi possível observar que os problemas de conservação decorrentes da exposição do sítio às intempéries naturais ao longo do tempo têm mantido um certo equilíbrio e, de modo geral, alterações bruscas não foram registradas. Por outro lado, o contrário foi observado com os problemas de conservação que têm sua origem nas intervenções humanas, muitos dos quais mostraram avanço considerável e preocupante.

\section{FORMAÇÃO DE RECURSOS HUMANOS}

O desenvolvimento contínuo e sistemático de diversos projetos de pesquisa no sítio Pedra do Cantagalo I tem focado a formação ou a qualificação de recursos humanos em seus diferentes níveis, como em (i) seis planos de trabalho de iniciação científica; (ii) quatro trabalhos de conclusão de curso de graduação; (iii) uma dissertação de mestrado; (iv) uma tese de doutorado; e (v) um plano de pesquisa de pós-doutorado. 


\section{PARCERIAS ACADÊMICO-CIENTÍFICAS}

A colaboração acadêmico-científica com diversos pesquisadores de diferentes universidades e centros de pesquisa no Brasil e no exterior tem sido um aspecto central, sem o qual os avanços pretendidos nas análises arqueométricas do sítio arqueológico Pedra do Cantagalo I seriam consideravelmente mais lentos, em alguns casos impossíveis. Nesse sentido, sólidas parcerias acadêmico-científicas foram empreendidas com pesquisadores da Universidade Federal de Minas Gerais (UFMG, em Belo Horizonte, Minas Gerais), do Centro de Desenvolvimento da Tecnologia Nuclear (CDTN; em Belo Horizonte, Minas Gerais), da Universidade Federal dos Vales do Jequitinhonha e Mucuri (UFVJM; em Diamantina, Minas Gerais), da Universidade de Coimbra (UC; em Coimbra, Portugal) e da Johannes Gutenberg-Universität Mainz (JGU; em Mainz, Alemanha).

\section{CONSIDERAÇÕES GERAIS}

A estratégia de pesquisa formulada para a investigação do sítio Pedra do Cantagalo I é ousada e desafiadora e diversas frentes de atuação ainda estão em pleno andamento. Trata-se de um sítio arqueológico contendo diversos tipos de materiais arqueológicos, cada um com natureza e complexidade próprias, exigindo do cientista múltiplos olhares.

Do ponto de vista da arqueometria, os exames físicos e as análises química, mineralógica, hiperfina, magnética e morfológica dos materiais arqueológicos revelam múltiplos desafios experimentais e exigem estratégias analíticas por conjunção de um número relativamente amplo de técnicas espectroscópicas, preferencialmente não-destrutivas. Na vasta maioria das vezes, as amostras são estruturalmente complexas, dos pontos de vista da nanomorfologia, têm amplas distribuições dos pequenos tamanhos das partículas, com estruturas química, cristalográfica, magnética e hiperfina que requerem interpretações, mais comumente, bem especiais, para se obter descrições fundamentais consistentes.

Algumas das técnicas analíticas utilizadas na investigação dos filmes de tinta de pinturas rupestres pré-históricas são mundialmente inéditas para esse tipo de material arqueológico, como é o caso da espectroscopia Mössbauer do ${ }^{57} \mathrm{Fe}$ em geometria de elétrons de conversão e da difratometria de raios X em ângulo de incidência rasante.

A adequada montagem do quebra-cabeças de informações obtidas do campo e do laboratório, capaz de contar a história dos grupos humanos antigos, é uma tarefa desafiadora.

No caldeirão de possibilidades analíticas, a arqueometria (que corresponde à aplicação de técnicas de exames e de análises, químicas, físicas ou biológicas, na investigação de materiais arqueológicos) tem um papel fundamental, uma vez que revela informações e detalhes nem sempre visualmente observáveis. Dados químicos e mineralógicos, por exemplo, não seriam obtidos de outra maneira se não fosse por meio de ferramentas analíticas, por exemplo, espectrométricas e difratométricas de raios X.

\section{Agradecimentos}

Ao Conselho Nacional de Desenvolvimento Científico e Tecnológico (CNPq), pelo apoio financeiro (processos 487148/2013-4 e 313431/2017-5); à Universidade Federal do Piauí (UFPI), pelo auxílio com transporte em algumas viagens de campo; à Financiadora de Estudos e Projetos (FINEP), pelo auxílio financeiro que possibilitou a compra do espectrômetro Mössbauer MIMOS II; à Fundação de Amparo à Pesquisa do Estado de Minas Gerais (FAPEMIG), pelos auxílios financeiros, que possibilitaram a compra de vários equipamentos da UFMG, utilizados na investigação de amostras do sítio Pedra do Cantagalo I; ao Centro de Desenvolvimento da Tecnologia Nuclear (CDTN), pelas análises de EDXRF, DRX, Mössbauer e VSM; à Universidade Federal de Minas Gerais (UFMG), pelas medidas de FTIR, CHN e Mössbauer; à Universidade Federal dos Vales do Jequitinhonha e Mucuri (UFVJM), pelas medidas de CHN e DRX; aos estudantes de IC: Andrews A Rodrigues, Yana RV Alves, Elnathan NL Costa, Heralda KSB Silva; aos estudantes de TCC: Petherson F Oliveira, Andrews A Rodrigues, Heralda KSB Silva, Elnathan NL Costa; à estudante de Mestrado: Heralda KSB Silva. 


\section{REFERÊNCIAS}

ARAÚJO, Igor Linhares de. O que os olhos não veem, os dados revelam: estudo arqueométrico de cerâmicas arqueológicas do sítio Lagoa do Portinho I. Dissertação (Mestrado em Arqueologia) - Universidade Federal do Piauí, Teresina, 2014.

BORGES, Jóina Freitas. Os senhores das dunas e os adventícios d'além-mar: primeiros contatos, tentativas de colonização e autonomia Tremembé na costa leste-oeste (séculos XVI e XVII). Tese (Doutorado em História) - Universidade Federal Fluminense, Niterói, 2010.

CAVALCANTE, Luis Carlos Duarte. Caracterização arqueométrica de pinturas rupestres pré-históricas, pigmentos minerais naturais e eflorescências salinas de sítios arqueológicos. Tese (Doutorado em Ciências - Química) - Universidade Federal de Minas Gerais, Belo Horizonte, 2012.

CAVAlCANTE, Luis Carlos Duarte; ALVES, Yana Raquel Viana. Caracterização mineralógica de pinturas rupestres do sítio Pedra do Cantagalo I por espectroscopia Raman. Relatório Final de Iniciação Científica - Edital PIBIC-CNPq-UFPI 2013-2014. Teresina: CPES-PROPESQ-UFPI, 2014.

CAVALCANTE, Luis Carlos Duarte; ALVES, Yana Raquel Viana; SILVA, Heralda Kelis Sousa Bezerra. Avaliação in situ dos problemas de conservação do sítio arqueológico Pedra do Cantagalo I. Rupestreweb, 2017.1, p. 1-13, 2017.

CAVAlCANTE, Luis Carlos Duarte; COSTA, Elnathan Nícolas Lima da. Análise arqueométrica de paleossedimentos do sítio Pedra do Cantagalo I: uma busca por marcadores químico-mineralógicos de atividade humana antiga. Relatório Final de Iniciação Científica - Edital PIBIC-CNPq-UFPI 2014-2015. Teresina: CPES-PROPESQ-UFPI, 2015.

CAVALCANTE, Luis Carlos Duarte; COSTA, Elnathan Nícolas Lima da. Caracterização química e mineralógica dos restos cerâmicos do sítio Pedra do Cantagalo I. Relatório Final de Iniciação Científica - Edital ICV-UFPI 2013-2014. Teresina: CPES-PROPESQ-UFPI, 2014.

CAVALCANTE, Luis Carlos Duarte; RODRIGUES, Andrews Araújo. Arte rupestre e problemas de conservação da Pedra do Cantagalo I. International Journal of South American Archaeology, n. 7, p. 15-21, 2010.

CAVAlCANTE, Luis Carlos Duarte; RODRIGUES, Andrews Araújo; COSTA, Elnathan Nícolas Lima da; SILVA, Heralda Kelis Sousa Bezerra; RODRIGUES, Pablo Roggers Amaral; OLIVEIRA, Petherson Farias de; ALVES, Yana Raquel Viana; FABRIS, José Domingos. Pedra do Cantagalo I: uma síntese das pesquisas arqueológicas. Arqueología Iberoamericana, v. 23, p. 45-60, 2014.

CAVALCANTE, Luis Carlos Duarte; SILVA, Heralda Kelis Sousa Bezerra da. Análise de pinturas rupestres do abrigo Pedra do Cantagalo I usando o espectrômetro Mössbauer miniaturizado MIMOS II. Relatório Final de Iniciação Científica - Edital PIBIC-CNPq-UFPI 2013-2014. Teresina: CPES-PROPESQ-UFPI, 2014.

CAVALCANTE, Luis Carlos Duarte; SILVA, Heralda Kelis Sousa Bezerra da; FABRIS, José Domingos; ARDISSON, José Domingos. Red and yellow ochres from the archaeological site Pedra do Cantagalo I, in Piripiri, Piauí, Brazil. Hyperfine Interactions, v. 238, n. 1, p. 22.1-22.7, 2017.

CAVAlCANTE, Luis Carlos Duarte; SILVA, Heralda Kelis Sousa Bezerra da; RODRIGUES, Andrews Araújo. Pedra do Cantagalo I: o desafio de preservar um patrimônio arqueológico. Vox Musei Arte e Patrimônio, v. 1, n. 2, p. 14-22, 2016.

FAURE, Martine; GUÉRIN, Claude; LUZ, Maria de Fátima da. Les parures des sépultures préhistoriques de l'abri-sous-roche d'Enoque (Parc National Serra das Confusões, Piauí, Brésil). Anthropozoologica, v. 46, n. 1, p. 27-45, 2011. 
GUIDON, N.; DELIBRIAS, G. Carbon-14 dates point to man in the Americas 32,000 years ago. Nature, v. 321, p. 769-771, 1986.

GUIDON, Niède; LUZ, Maria de Fátima da. Sepultamentos na Toca do Enoque (Serra das Confusões-Piauí). Fumdhamentos, n. 8 , p. $115-123,2009$.

IPHAN-UFPI-FUNDEC. Cadastramento e mapeamento dos sítios arqueológicos do Piauí - Relatório de Atividades da 4a Etapa. Teresina: NAP-UFPI/IPHAN, 1997.

KINOSHITA, A.; FIGUEIREDO, A. M. G.; FELICE, G. D.; LAGE, M. C. S. M.; GUIDON, N.; BAFFA, O. Electron spin resonance dating of human teeth from Toca da Santa shelter of São Raimundo Nonato, Piauí, Brazil. Nuclear Instruments and Methods in Physics Research B, v. 266, p. 635-639, 2008.

KINOSHITA, Angela; SKINNER, Anne R.; GUIDON, Niede; IGNACIO, Elaine; FELICE, Gisele Daltrini; BUCO, Cristiane de A.; TATUMI, Sonia; YEE, Márcio; FIGUEIREDO, Ana Maria Graciano; BAFFA, Oswaldo. Dating human occupation at Toca do Serrote das Moendas, São Raimundo Nonato, Piauí-Brasil by electron spin resonance and optically stimulated luminescence. Journal of Human Evolution, v. 77, p. 187-195, 2014.

LESSA, Andrea; GUIDON, Niéde. Osteobiographic analysis of skeleton I, Sítio Toca dos Coqueiros, Serra da Capivara National Park, Brazil, 11,060 BP: first results. American Journal of Physical Anthropology, v. 118, p. 99-110, 2002.

OLIVEIRA, Petherson Farias de. Análise tipológica preliminar da cultura material do sítio Pedra do Cantagalo I e seu entorno. Trabalho de Conclusão de Curso (Graduação em Arqueologia e Conservação de Arte Rupestre) - Universidade Federal do Piauí, Teresina, 2013.

PESSIS, Anne-Marie; GUIDON, Niède. Dating rock art paintings in Serra de Capivara National Park - combined archaeometric techniques. Adoranten, p. 49-59, 2009.

PEYRE, Evelyne; GUÉRIN, Claude; GUIDON, Niède; COPPENS, Yves. Des restes humains pléistocènes dans la grotte du Garrincho, Piauí, Brésil. Comptes Rendus de l'Académie des Sciences de Paris, v. 327, p. 335-360, 1998.

SANTOS, G. M.; BIRD, M. I.; PARENTI, F.; FIFIELD, L. K.; GUIDON, N.; HAUSLADEN, P. A. A revised chronology of the lowest occupation layer of Pedra Furada Rock Shelter, Piauí, Brazil: the Pleistocene peopling of the Americas. Quaternary Science Reviews, v. 22, p. 2303-2310, 2003.

SILVA, Heralda Kelis Sousa Bezerra da. Análise químico-mineralógica de ocres e a busca por correlações arqueológicas com os pigmentos de pinturas rupestres do sítio Pedra do Cantagalo I. Dissertação (Mestrado em Arqueologia) - Universidade Federal do Piauí, Teresina, 2018.

SILVA, Heralda Kelis Sousa Bezerra da; CAVALCANTE, Luis Carlos Duarte. Estratégias de campo e de laboratório utilizadas na investigação do sítio arqueológico Pedra do Cantagalo I. Arqueología Iberoamericana, v. 33, p. 35-41, 2017.

SILVA, Heralda Kelis Sousa Bezerra da; CAVALCANTE, Luis Carlos Duarte; FABRIS, José Domingos. Características químico-mineralógicas de fontes de pigmentos minerais em depósitos naturais do entorno do sítio arqueológico Pedra do Cantagalo I, em Piripiri, Piauí, Brasil. Arqueología Iberoamericana, v. 36, p. 36-42, 2017.

VALLADAS, H.; MERCIER, N.; MICHAB, M.; JORON, J. L.; REYSS, J. L.; GUIDON, N. TL age-estimates of burnt quartz pebbles from the Toca do Boqueirão da Pedra Furada (Piaui, Northeastern Brazil). Quaternary Science Reviews, v. 22, p. 1257-1263, 2003.

WATANABE, Shigueo; AYTA, Walter Elias Feria; HAMAGUCHI, Henrique; GUIDON, Niède; LA SALVIA, Eliany S.; MARANCA, Silvia; BAFFA FILHO, Oswaldo. Some evidence of a date of first humans to arrive in Brazil. Journal of Archaeological Science, v. 30, p. 351-354, 2003.

Recebido em: 01/06/2018 Aprovado em: 23/07/2018 Publicado em: $30 / 11 / 2018$ 